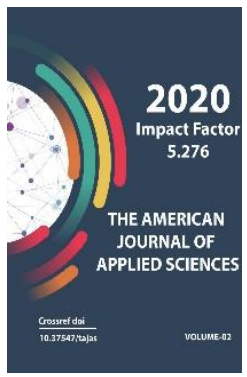

\title{
Student Creativity In Problem Experiments In Physics
}

\author{
B.Imanov \\ Candidate Of Pedagogical Sciences, Associate Professor, Head Of The Department Of \\ Education Quality Control, Termez State University, Uzbekistan
}

\footnotetext{
Journal Website: http://usajournalshub.c om/index,php/tajas

Copyright: Original content from this work may be used under the terms of the creative commons attributes 4.0 licence.
}

\section{ABSTRACT}

This article discusses the creativity of students in problem-solving experiments in physics, the cybernetic, psychological, pedagogical nature of the experiment, as well as types of creative situations, criteria for assessing student creativity in problem-solving experiments in physics and their logical relationship.

\section{KEYWORDS}

Experience, creativity, creative activity, discussion, critical thinking, analysis, creativity, problem.

\section{INTRODUCTION}

One of the objects of the process of problemsolving in physics is the assessment of student creativity. Student creativity in problem- solving can be understood from the following perspectives: 
a) Structure and content;

b) Types of problem experiments;

c) The abilities and qualities of the student in any problematic experiment in physics;

d) Effective methods for performing problem experiments in physics. It is important to draw the reader's attention to the broad use of the term "experiment" in science. For example, different definitions are given to the term experiment. These are:

1. Set a goal and strive to achieve it.

2. Assignments and tasks.

3. Questions and assignments on problem practice based on the acquired knowledge and ideas.

4. Examining the theoretical knowledge, practical skills and abilities of the student in the process of performing a problem experiment.

Here the concept of experience can be viewed from different perspectives. For us, the cybernetic, psychological, pedagogical point of view is more interesting. From a cybernetic point of view, experience is the result of an action that determines the resolution of a situation.

\section{Materials And Methods}

There are several approaches to interpreting the concept of experience in the psychology literature. The most common of these is the concept given by AN Lermontov: "Experience is a situation that requires action from the subject." According to O.K Tikhomirov, "experience" is a goal expressed in certain conditions. There is a broader definition of the concept of "experience" and the psychological analysis of its components. For example, L.L. Gurova describes "Experiment" as an object of thinking activity, which requires theoretical questions and answers or some practical changes by looking for conditions that reveal the connection between its known and unknown elements.If we analyze the concept of "experience in a psychological context" from a pedagogical point of view, we can say the same about the experience that occurs in the process of creative activity. Problem-based experience can be both an object of creative activity and a means of organizing creative activity. When performing a problem experiment in physics, the conditions, goals, and requirements of creative activity, directly or indirectly, are given.

Analysis and understanding of the above concepts from a pedagogical point of view shows that different situations can arise in solving a problematic experiment from physics. In particular, students may experience creative situations, such as productive, that require the application of a previously known algorithm, method, method of activity. The creative situation requires the resolution of some dialectical contradictions. A creative situation requires the reader to look for a new method to get out of the problem. They can be said to stimulate the development of the student's creative ability at the same time. Examples of creative situations include:contentious situation; critical thinking, a situation that requires evaluation, a situation that requires the application of analogies; assumptions, hypotheses, and so on.It is worth noting that creative situations can lead to a problematic experiment from physics, or a problematic experience itself can create and create a creative situation.In our opinion, a very close "creative situation" and a "problematic situation" mean a broader concept. 
A problematic situation represents a contradiction, and a task that is related to what the learner should know, be able to do, what he or she should know, and be able to accomplish in order to resolve the conflict. Such an experience is not always the starting point of perception. Often some contradiction is the result of reviewing the activity, which then becomes a problem; it takes on the appearance of some kind of 'experience', taking into account 'goals' and 'conditions' in time.It should be noted that putting the "problem" and then "clarifying the experience does not always lead to its fulfillment." Because, according to most scholars, putting a problematic experiment right does not in many ways lead to finding its fulfillment, but it does lead to its fulfillment.It should be borne in mind that the problem may not have the objective conditions and means to unravel it at the present stage of development of science. It takes a long time for scientific problems to be solved. For example, scientists have long been engaged in connecting with the era of civilizations. The identification of specific problematic experiments in this area has begun in recent years, and scientists argue that their implementation can be done in the near future. There are also ideas that, for example, a problematic experience cannot be solved naturally at all.As mentioned, from a psychological perspective, experience is often seen as a model of some kind of ratio of human activity and purpose. They also agree with psychologist S.L. Rubinstein. He views "experience" as a "ratio of purpose and condition." But in recent years, scientists have been debating the question of what is primary. What is primary? There are conflicting views on whether it is an experience or an activity, that is, whether the activity produces an experience or whether the experience drives the activity. A.M.Matyushkin,
L.L.Gurova, L.M.Friedman, T.V.Kudryavtsev The subject is not necessary to express the concept of "experiment", because it consists of a subjective task on the structure of the experiment, a seeker who expresses knowledge and needs to be found are believed to be expressed in a form or word denoting the conditions of the relationship betweenA.N.Leontev, G.S.Kaskova, Ya.A.Ponomaryov's research, for example, A.N.Leontev's definition of the concept of "experience" is one of the acceptable definitions. According to A.N. Leontev, "experience" is defined as a situation that requires some action from the object.In our opinion, both definitions are correct. Why does the reader see conflict resolution as a problem question or an analysis of the expression of a problematic experience? In this case, the experience itself is the result of some activity.Thus, pedagogical goals are the result of an activity for the learner who has set the problem experience, and will be the beginning of the activity for the learner who performs it. Nowadays, the second option is more widely used in practice, i.e. the teacher puts a ready-made, correctly expressed experience to the students 'attention. It also requires a high level of intellectual qualities from the subject to develop creative ability when the subject "identifies" the conflict at the beginning of the activity.

\section{RESULTS AND DISCUSSIONS}

Two important features of educational experience in the field of pedagogical psychology and didactics are highlighted. For example, D.I Bogoyavlensky wrote: "any material can be a subject of study for a scientist only if there is a clear experience that guides and encourages learning activities." In other words, one of the hallmarks of a 
problematic experience is as a specific form that makes up the content of these learning materials. Summarizing the above,it is possible to come to such a conclusion from the pedagogical point of view, understanding the content of the concept of problematic experience.Problem-based laboratory work is organized in such a way that the teacher can create a creative "problem" situation for students. Indicates the purpose, condition, requirement of direct or indirect creative activity. In this process, the student acquires knowledge, skills, abilities and competencies and develops personal creative abilities. He can then analyze the problematic experience, continuing in different directions. It is important to categorize the types of problematic experiences in terms of nurturing the student's creative ability and selfeducation. The examination and conclusions in this direction give the following results: The proposed classification is considered open. In creative activity situations, in addition to the experience mentioned above, you have to perform a problematic experience. In doing so, the qualities of the reader are seen and developed. For example, we consider what the most effective method for performing a mental experiment is to evaluate the results of a mental experiment. At the same time, the analysis of the intellectual experience given in the classification, the development of the creative ability of the readers shows that the opinions of the authors who study the problems of verification are wrong. They explain such creative outcomes as the development of intellectual, creative abilities. The structure of creative skills is complex, but the composition of the stages of creative activity is much wider.

Problem-based learning is used in the learning process for the following purposes: a) Development of creative abilities of students;

b) Students acquire new knowledge about concepts, rules, theories, postulates, principles, methods, tools and rules;

c) Students acquire mental and practical skills;

d) Organize students' creative abilities;

e) Monitoring students' knowledge and skills;

f) Increase the relevance of students' knowledge, skills, creative abilities.

Pedagogical analysis of the specificity of creative activity, first of all, requires a broad understanding of the concept of "creativity".This is a generally accepted definition of the concept. Such creativity is a type of student activity, primarily novelty.Russian psychologist LS Vygotsky agrees: "Creative activity is the activity of the student that creates something new." The encyclopedic dictionary says that "Creation is an activity that is new in many respects and unique, and creates a socio-historical thing. Creativity is a human quality, that is, always a creative subject of creative activity, a process of development in nature."The difference between this expression and philosophical, psychological, pedagogical ideas is that "creation" is not considered to be the same as "development" in this case.Ya.A. Ponomaryov defines the concept of "creation" and explains it as the same as the concept of "development". "Creativity is a general criterion of creativity," he writes in "Pedagogical Psychology." "The concept of creativity has been studied with interest by many scientists in recent years. In philosophy, A.G. Spirker gives the following definition of the concept of "creation": "Creativity is a thought and practical activity, as a result of which irreplaceable riches are created, a new 
fact, a feature. Laws will be known, and ways will be created to examine and transform the material world and spiritual culture. "Such a description is a sign of novelty for pedagogical research, the objective and subjective significance of the creative process. It should be noted that the above phrase is taken from the introductory speech of AG Spirker in the book "Science and Creativity" by the Bulgarian philosopher G. Girgonov.G. Grigonova nalyzes the concept of "creation" and draws attention to their type, level and differences. "The word creation is specific to the student's thinking and student activity, and it consists of activities in which, in the first place, objects and events that do not exist in objective life occur. For example, knowledge of reality or material, inventions (weapons and machines); second, man-made material and spiritual inventions are further developed; thirdly, what exists is subjectively processed. " Creativity is narrow and secondary creativity can be observed when it comes to the stage or level of development of an existing creativity, placing high demands on the reader's thinking and human movement.The second type of creativity is often associated with "discovery" and "invention". "Practical creativity is the search for, finding, and resolving specific connections and relationships. Its unique tool is the law, the idea of developing a legal relationship. "In the analysis of creativity as a specific type of student activity, along with the signs of "novelty" and "social significance", it is necessary to show the sign of "progressivity", because the social significance varies for social groups. This sign is often overlooked. According to SS Goladentrich, "The nature of creative activity is the creation of something new that contributes to the development of man and society. It is said that the content of creation does not coincide with the opposite activity. However, S.S.Goladentrich and F.O.Kondrashenko are right on the one hand. "Creativity is a student activity, a key area of student formation," he says.

\section{CONCLUSION}

Thus, creation is considered as a type of human activity, expressed by the following signs, which are not always separate, but integrative, they are manifested in unity:a) the presence of contradictions in a problematic situation or in the performance of an experiment of a creative content; b) social and personal significance and progress, ie it contributes to the development of society and the individual; $c$ ) the existence of objective social, material conditions for creativity; g) subjective personal qualities for creativity - the presence of knowledge, skills, passion, creative ability, the presence of conditions; $d$ ) novelty of process and result.If any of these characters are excluded, then there is no creative activity, that is, the activity is not considered creative.

\section{REFERENCES}

1. Appendix 1 to the Resolution of the President of the Republic of Uzbekistan dated 08.10.2019 №5847 "Concept of development of the higher education system of the Republic of Uzbekistan until 2030".

2. Decree of the President of the Republic of Uzbekistan PF-5535 dated 05.09.2018 "On additional measures to improve the management system of public education."

3. Rubenstein

S.L.Problemyobshcheypsychologii. - $M$.: Pedagogy, 1976.

4. Simonov

V.P.Diognostikastepeniobuchennostiuchas hixsya, - M .: 199-206 s. 
Doi: https://doi.org/10.37547/tajas/Volume02Issue09-28

5. N.I. Amirov, Problems and effective ways of developing creative qualities in teachers, 2018. 